\title{
Magnetic Resonance Imaging Evaluation of L5-S1 Intervertebral Disc Degeneration in Japanese Women
}

\author{
Hiroaki Hagiwara ${ }^{1}$, Hirofumi Shibata ${ }^{1}$, Hideya Sakakibara $^{2}$, Tomio Inoue ${ }^{1}$ \\ ${ }^{1}$ Department of Radiology, Yokohama City University Graduate School of Medicine, Yokohama, Japan \\ ${ }^{2}$ Department of Obstetrics and Gynecology, Yokohama City University Graduate School of Medicine, Yokohama, Japan
}

\begin{abstract}
Study Design: Retrospective case series.
Purpose: To calculate the prevalence of L5-S1 intervertebral disc degeneration (IDD) by evaluating gynecological disease findings, obtained by pelvic magnetic resonance imaging (MRI), and reveal the risk factors for IDD by analyzing its relationship with age, sacral structure, body mass index (BMI), number of deliveries, and intrapelvic space-occupying lesions.

Overview of Literature: Age, obesity, height, smoking history, occupation, and lumbosacral structure are reportedly the main factors of lumbar IDD. However, in women, the relationship of IDD with obstetric and gynecological history is unclear.

Methods: The presence of L5-S1 IDD was evaluated on sagittal T2-weighted pelvic MRI during gynecological evaluations in 660 Japanese women. We measured the sacral table angle (STA), sacral kyphosis angle (SKA), and intrapelvic space-occupying lesion size. Age, height, weight, BMI, number of deliveries, lumbosacral structure, size of space-occupying lesions, and presence of uterine leiomyoma based on medical records were compared between the IDD-positive and IDD-negative groups.

Results: Lumbosacral IDD was observed in 405 cases (61.4\%), and its prevalence increased with age. Differences in age, height, weight, BMI, and number of deliveries between the IDD-positive and -negative groups were significant, but differences in STA, SKA, and presence of uterine leiomyoma and space-occupying lesion size were not. Logistic regression analysis indicated that age, BMI, and STA were risk factors for lumbosacral IDD.

Conclusions: Age is the biggest risk factor for lumbosacral IDD in Japanese women, with BMI and STA also contributing to its development. However, SKA and obstetric and gynecological history were not significantly involved.
\end{abstract}

Keywords: Intervertebral disc degeneration; Magnetic resonance imaging; Lumbosalral region; Body mass index; Reproductive history

\section{Introduction}

Lumbar intervertebral disc degeneration (IDD) is often incidentally detected on pelvic magnetic resonance imaging (MRI). The prevalence of IDD is reported to be high among the population. In such cases, a greater degree of degeneration than that expected at a particular age is commonly observed. However, the frequency of IDD differs among the studies [1-3].

The primary cause of IDD is considered to be a lack of nutrition to disc cells [4]. In addition, environmental factors such as smoking, obesity, and lack of exercise can decrease blood flow to the lumbar artery and promote the development of IDD [5,6]. Many studies have used MRI

Received Oct 19, 2013; Revised Dec 19, 2013; Accepted Jan 8, 2014

Corresponding author: Hiroaki Hagiwara

Department of Radiology, Yokohama City University Graduate School of Medicine,

3-9 Fukuura Kanazawa-ku, Yokohama 236-0004, Japan

Tel: +81-45-7872696, Fax: +81-45-786-0369, E-mail: hhagi1936@gmail.com 
to analyze the prevalence of IDD, and its main causes have been well researched. In addition, histological findings from surgical specimens have been used to show that increased body mass index (BMI) is a risk factor for IDD $[7,8]$.

A relationship between IDD and pregnancy has been reported in women [9]; however, in another report, IDD is found to be an age-related change unrelated to pregnancy [3]. The rapid increase in uterine volume that occurs during pregnancy is believed to induce stress on the pelvis and lumbar vertebrae. However, we were unable to identify reports that examined the effect of intrapelvic space-occupying lesions or gynecological history on the lumbar vertebrae.

Previous studies have indicated a relationship between IDD and lumbosacropelvic structure [10,11]. The degree of intervertebral disc degeneration increased in parallel with a decrease in the sacral kyphosis angle and with the increase in the sacral table angle [10].

In the present study, we aimed to determine the risk factors for IDD in Japanese women, while focusing on lumbosacral structures, number of deliveries, and intrapelvic space-occupying lesions.

\section{Materials and Methods}

\section{Patient population}

The ethics committee of the Yokohama City University Hospital approved the study plan. Magnetic resonance (MR) images of patients with gynecological disease from 2011 to 2012 were retrospectively evaluated. Excluded were the cases where the BMI could not be estimated due to missing height or weight data and those in which the lumbosacral discs were outside the image range; and thus, 660 subjects (mean age, $48.2 \pm 15.6$ years; range, 10-92 years) were eventually included in the present study.

Height and weight data were obtained from medical records, and the data obtained on the day closest to the MRI evaluation day were recorded. BMI was calculated as weight $/$ height ${ }^{2}\left(\mathrm{~kg} / \mathrm{m}^{2}\right)$. Similarly, the value for the number of deliveries was obtained from medical records at the time of the MRI evaluation.

\section{MRI of the pelvis}

The MRI examinations were performed using an 1.5-Tesla MRI device (Symphony, Siemens, Germany; or Intera, Philips, Netherlands). The sagittal T2-weighted images (repetition time, 3500-4000 ms; echo time, 92-100 ms; slice thickness, $6 \mathrm{~mm}$; and interslice gap, $8 \mathrm{~mm}$ ) obtained were evaluated.

The presence and degree of intervertebral disc degeneration was assessed on sagittal T2-weighted MR images passing through the midsagittal line. All measurements were performed using PACS (Synapse, Fujifilm Medical Systems, Tokyo, Japan). In addition, we used the modified Pfirrmann classification (grades 1-5) to assess the degree of IDD on T2-weighted images [12-14]. Discs with grades 1-2 were considered to be normal, whereas discs with grades 3-5 were considered to be degenerated (Fig. 1). IDD was evaluated by two experienced radiologists who were blinded to all clinical data. The inter-rater reliability between the radiologists was nearly perfect $(\kappa, 0.98)$. Any discrepancies noted were resolved by agreement between the two radiologists after reviewing the findings.

The lumbosacral parameters were also analyzed by us-
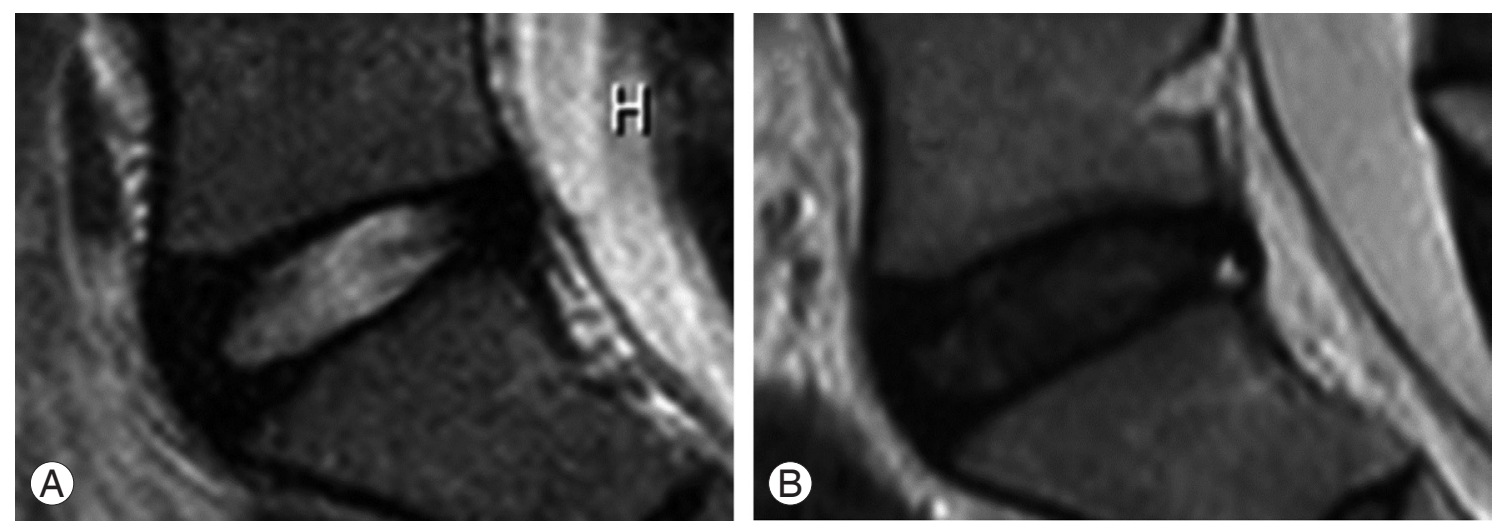

Fig. 1. Magnetic resonance imaging (T2-weighted sagittal images) of the L5-S1 intervertebral disc. (A) Grade 2, classified as a normal disc. (B) Grade 3, classified as degenerated disc. 
ing the same image. To minimize random errors, each measurement was repeated twice, and the average value was recorded. The sacral table angle (STA), described by Österman and Österman [15], is the angle formed by the upper and posterior surfaces of the sacral endplate. The sacral kyphosis angle (SKA), described by Ergun et al. [10], is the angle formed by the line connecting the midpoints of the upper and lower endplates of S1 and the line connecting the midpoints of the upper endplate of S2 and the lower endplate of S4 (Fig. 2) [10].

Similarly, space-occupying lesions in the pelvis, including uterine leiomyoma and ovarian masses, were measured using sagittal T2-weighted images. The long axis was the longest diameter of the uterus, including the uterine leiomyoma; and the short axis was the diameter located orthogonally to the long diameter. Multiplication of the long axis with the short axis yielded the value for the volume of the space-occupying lesion, and was defined as the pelvic mass index (PMI) (Fig 3). In cases where the long axis of ovarian lesions was longer than the long axis of the uterus, the ovarian lesion value was used for estimating the PMI. Cases that could not be measured due to hysterectomy were treated as missing values.

\section{Statistical analysis}

All statistical analyses were performed using SPSS ver. 21.0 for Windows (SPSS Inc., Chicago, IL, USA). The cases were divided into the following five groups by age:
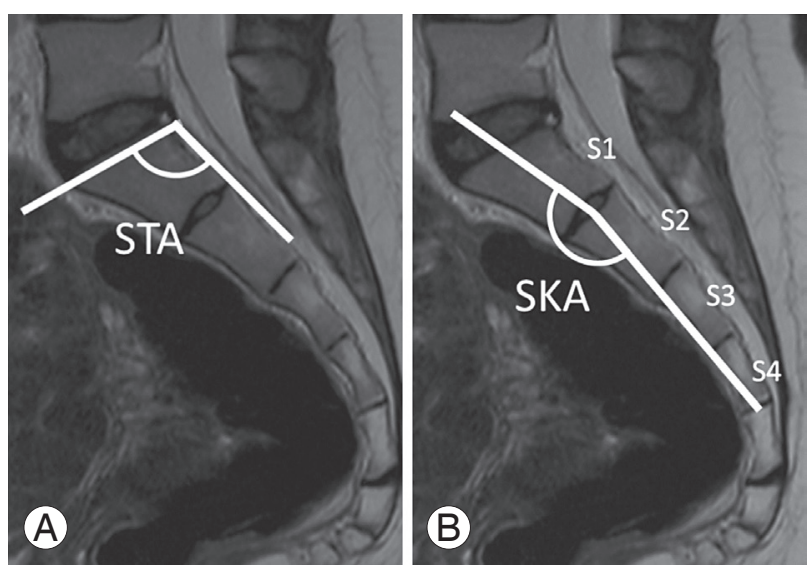

Fig. 2. Measurement of the sacral structure. (A) Sacral table angle (STA) is the angle formed by the upper and posterior surfaces of the sacral endplate. (B) Sacral kyphosis angle (SKA) is the angle formed by the line connecting the midpoints of the upper and lower endplates of $S 1$ and the line connecting the midpoints of the upper endplate of S2 and the lower endplate of S4.
$<30$ years, $30-39$ years, $40-49$ years, $50-59$ years, and $\geq 60$ years. Comparisons between the age groups for IDD prevalence and other variables were performed using the Pearson chi-square test or analysis of variance (ANOVA; the Kruskal-Wallis test). For all cases, correlations between variables were analyzed using Pearson's correlation coefficient.

The variables were compared between the IDD-positive group and the IDD-negative groups for all cases, as well as after dividing the subjects into age groups, and were conducted using Student's $t$-test, Welch's $t$-test, Pearson's chi-square test, and the Mann-Whitney $U$-test, as appropriate. A $p$-value of $<0.05$ was considered statistically significant.

Subsequently, logistic regression models were used to compare descriptive data according to the presence or absence of IDD. Variables with a $p$-value of $<0.25$ in the univariate analysis were used as input variables for multiple logistic regression analysis. To avoid multicollinearity of descriptive data, the weight, height, and delivery data were not used in the models.

\section{Results}

IDD was observed in 405 of the 660 cases $(61.4 \%)$. The

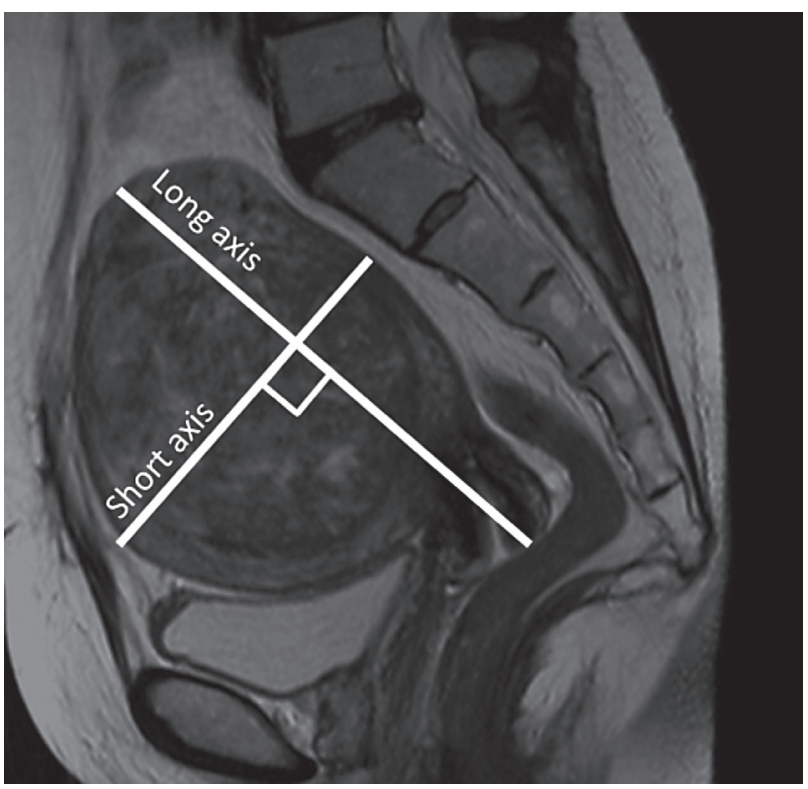

Fig. 3. Measurement of the intrapelvic space-occupying lesion. The longest diameter including the uterine leiomyoma was measured as the long axis and the diameter located orthogonally to that was measured as the short axis. The value obtained on multiplication of the long axis with the short axis was used as the volume of the spaceoccupying lesion, and was defined as the pelvic mass index. 
prevalence of IDD increased with age; and the difference was found to be statistically significant $(p<0.001)$ (Table 1 , Fig. 4). Subjects aged $\geq 60$ years exhibited an IDD prevalence of $92.2 \%$.

Although no significant differences were noted in SKA and STA between the age groups, significant differences were observed in certain other variables. In particular, age and the number of deliveries exhibited a weak positive correlation $(r=0.487)$, whereas age and height displayed a weak negative correlation $(r=-0.412)$ (Table 2).

After dividing all cases into IDD-positive and IDDnegative groups, significant differences were observed for age, height, weight, BMI, and number of deliveries, but not for STA, SKA, presence of uterine leiomyoma, or PMI $(p<0.001)$ (Table 3$)$. In order to exclude the factor of age, similar comparisons were performed within each age group. We noted significant differences in the age and the number of deliveries in subjects aged $<30$ years; in height and weight in subjects aged 30-39 years; in weight and BMI in subjects aged $40-49$ years; and in age in subjects aged $\geq 60$ years.

Logistic regression was used to calculate the odds ratio and $95 \%$ confidence interval, after simultaneously controlling for potential confounders in all the included cases. The results indicated that age (odds ratio, 1.095;

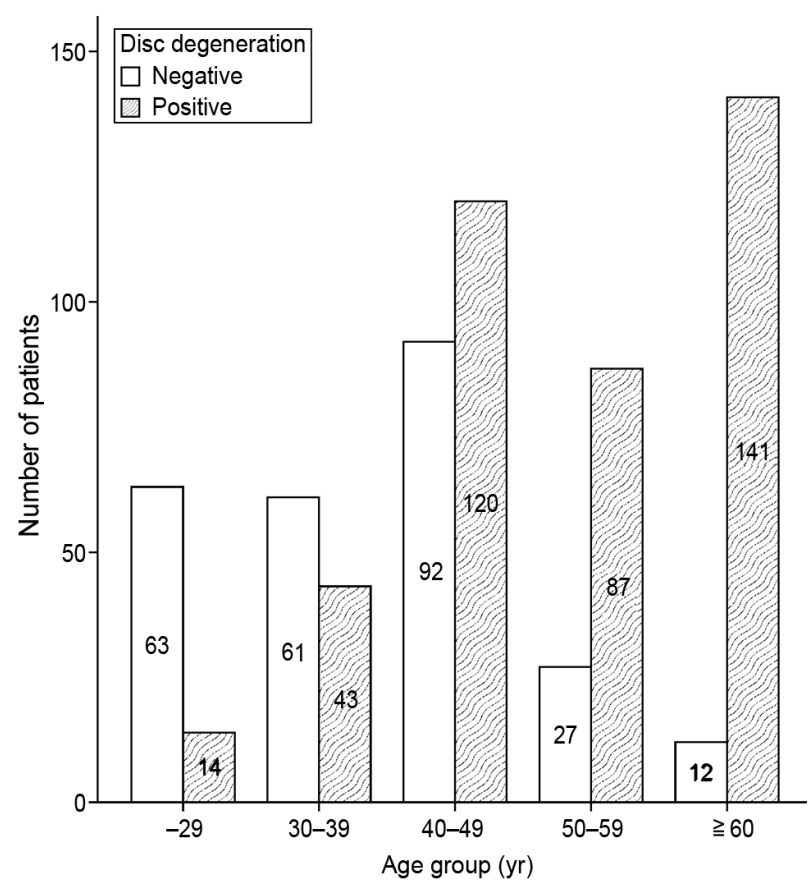

Fig. 4. Prevalence of $L 5-S 1$ intervertebral disc degeneration according to the age groups. $p<0.001$ ), BMI (odds ratio, 1.056; $p=0.023$ ), and STA (odds ratio, 1.034; $p=0.034$ ) were significant risk factors for IDD, but the odds ratios were all low (Table 4).

\section{Discussion}

IDD is reportedly caused by a variety of factors [16]. Powell et al. [3] reported that the prevalence of IDD among women increased linearly with age, reaching a value of 50\% among women in their 30s and $90 \%$ among women in their 70s [3]. In the present study, we noted similar rates of IDD prevalence: $41.3 \%$ in subjects aged $30-39$ years; and $92.2 \%$ in subjects aged $\geq 60$ years. Only a few studies that quantitatively evaluated the effect of aging on IDD have been published, although certain studies have indicated the annual progression of degeneration $[17,18]$. Using radiography, Hassett et al. [19] demonstrated the occurrence of degeneration as narrowing of the disc space; and they reported an odds ratio of 1.2-1.7 for a comparison between subjects aged $<50$ years and $>50$ years. In the present study, regression analysis indicated an odds ratio of $1.095(p<0.001)$ for age. Although the odds ratio is fairly low, it is the highest among the factors assessed, and can thus be considered as a valid result in comparison with those of the previous studies.

The association between lumbar IDD and BMI has been indicated by assessing images $[7,20,21]$ and the results of the histological evaluation of surgical specimens [8] in subjects with a variety of characteristics, including age, race, and body weight. In the present study, we also noted a significant difference in BMI between IDD-positive and IDD-negative cases. Moreover, regression analysis indicated an odds ratio of $1.056(p=0.023)$ for BMI, thus confirming the BMI as a significant risk factor for IDD. Furthermore, analyses of the different age groups showed significant differences for BMI and weight in subjects aged 40-49 years, thereby suggesting that BMI was a considerable risk factor for middle-aged women.

The lumbosacral structure is also a major factor in IDD $[10,11]$. The present study did not identify a correlation between STA and SKA or between these factors and age, number of deliveries, or any other variable. This indicates that STA and SKA are congenital characteristics that are not influenced by the environment. However, Ergun et al. has reported a large STA value and small SKA value to be anatomical factors that may cause IDD [10]. These findings contrast with those of the present study, wherein 
Table 1. Descriptive statics for all included cases according to the age group

\begin{tabular}{|c|c|c|c|c|c|c|c|}
\hline Age group (yr) & $\begin{array}{c}<30 \\
(n=77)\end{array}$ & $\begin{array}{c}30-39 \\
(n=104)\end{array}$ & $\begin{array}{c}40-49 \\
(n=212)\end{array}$ & $\begin{array}{c}50-59 \\
(n=114)\end{array}$ & $\begin{array}{c}\geq 60 \\
(n=153)\end{array}$ & $p$-value & $\begin{array}{c}\text { All cases } \\
(n=660)\end{array}$ \\
\hline Disc degeneration & & & & & & $<0.001^{a)}$ & \\
\hline Positive (\%) & 14 (18.2) & 43 (41.3) & $120(56.6)$ & 87 (76.3) & $141(92.2)$ & & 405 (61.4) \\
\hline Negative (\%) & 63 (81.8) & $61(58.7)$ & $92(43.4)$ & 27 (23.7) & $12(7.8)$ & & $255(38.6)$ \\
\hline Height (cm) & & & & & & $<0.001^{\text {b) }}$ & \\
\hline Mean & 159.0 & 159.8 & 158.4 & 157.3 & 152.7 & & 157.2 \\
\hline SD & 5.5 & 5.5 & 5.7 & 5.4 & 5.7 & & 6.2 \\
\hline Weight (kg) & & & & & & $0.001^{b)}$ & \\
\hline Mean & 52.4 & 54.8 & 57.1 & 55.5 & 53.2 & & 55.0 \\
\hline SD & 9.0 & 8.2 & 12.4 & 13.9 & 12.7 & & 11.9 \\
\hline $\mathrm{BMI}\left(\mathrm{kg} / \mathrm{m}^{2}\right)$ & & & & & & $0.001^{b)}$ & \\
\hline Mean & 20.7 & 21.5 & 22.8 & 22.3 & 22.8 & & 22.3 \\
\hline SD & 3.5 & 3.0 & 5.3 & 5.1 & 5.4 & & 4.9 \\
\hline $\operatorname{STA}\left({ }^{\circ}\right)$ & & & & & & $0.751^{b)}$ & \\
\hline Mean & 101.1 & 101.4 & 100.7 & 101.3 & 100.4 & & 100.9 \\
\hline SD & 6.2 & 7.5 & 5.5 & 6.0 & 5.5 & & 6.0 \\
\hline SKA $\left(^{\circ}\right)$ & & & & & & $0.286^{b)}$ & \\
\hline Mean & 164.1 & 163.1 & 163.7 & 161.0 & 163.3 & & 163.1 \\
\hline $\mathrm{SD}$ & 10.9 & 10.9 & 15.5 & 12.0 & 11.2 & & 12.8 \\
\hline UL & & & & & & $<0.001^{\text {a) }}$ & \\
\hline Present (\%) & $8(10.4)$ & $47(45.2)$ & 133 (62.7) & $56(49.1)$ & $43(28.1)$ & & 287 \\
\hline Absent (\%) & $69(89.6)$ & 57 (54.8) & 79 (37.3) & $58(50.9)$ & $110(71.9)$ & & 373 \\
\hline PMl & & & & & & $<0.001^{\text {b) }}$ & \\
\hline Mean & 4319.7 & 6186.2 & 7632.1 & 6268.2 & 5205.5 & & 6284.5 \\
\hline SD & 3982.1 & 4093.7 & 4849.6 & 4716.2 & 7030.5 & & 5300.4 \\
\hline Delivery & & & & & & $<0.001^{\text {b) }}$ & \\
\hline Mean & 0.13 & 0.53 & 0.89 & 1.36 & 1.83 & & 1.04 \\
\hline Range & $0-2$ & $0-4$ & $0-4$ & $0-4$ & $0-6$ & & $0-6$ \\
\hline
\end{tabular}

SD, standard deviation; BMI, body mass index; STA, sacral table angle; SKA, sacral kyphosis angle; UL, uterine leiomyoma; PMI, pelvic mass index.

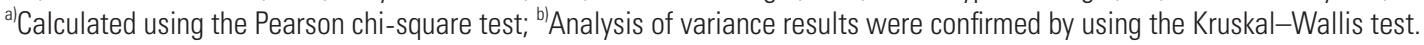

even a small SKA value does not show any association with IDD at L5-S1. Moreover, no significant difference in the average STA was observed between the group with degeneration and the group without, although regression analysis yielded an odds ratio of 1.034 ( $p=0.034)$. This indicates that STA can be a significant predictive variable of IDD (with a mean \pm SD of $100.9 \pm 6.0$ ), but its influence in causing IDD is believed to be small.

Low back pain (LBP) during pregnancy is a very common symptom, and considerable research has been performed on its prevalence and main causes [22-24].
According to Kovacs et al. [23], a history of LBP (related or unrelated to previous pregnancy or postpartum), LBP surgery, and anxiety were the factors strongly associated with pregnancy-related LBP. Moreover, Gruber et al. [25] verified the presence of pregnancy-associated plasma protein-A in intervertebral discs, proposing it to be involved in IDD. In addition, as childbirth is involved in IDD, a history of delivery is believed to be associated with a higher prevalence of LBP in middle-aged women [26]. Imaging examinations during pregnancy occasionally indicate the presence of disc bulging and herniation. 
Table 2. Pearson's correlation coefficient

\begin{tabular}{|c|c|c|c|c|c|c|c|c|}
\hline & Age & Height & Weight & $\mathrm{BMI}$ & STA & SKA & PMI & Delivery \\
\hline \multicolumn{9}{|l|}{ Age } \\
\hline Correlation coefficient & 1 & $-0.412^{* *}$ & -0.028 & $0.117^{* *}$ & -0.035 & -0.009 & -0.025 & $0.487^{* *}$ \\
\hline$p$-value & & 0.000 & 0.466 & 0.003 & 0.376 & 00.818 & 0.536 & 0.000 \\
\hline \multicolumn{9}{|l|}{ Height } \\
\hline Correlation coefficient & $-0.412^{* *}$ & 1 & $0.222^{* *}$ & $-0.141^{* *}$ & $0.104^{* *}$ & $-0.087^{*}$ & $0.088^{*}$ & $-0.205^{* *}$ \\
\hline$p$-value & 0.000 & & 0.000 & 0.000 & 0.008 & 0.026 & 0.030 & 0.000 \\
\hline \multicolumn{9}{|l|}{ Weight } \\
\hline Correlation coefficient & -0.028 & $0.222^{* *}$ & 1 & $0.931^{* *}$ & -0.064 & -0.008 & $0.164^{* *}$ & -0.005 \\
\hline$p$-value & 0.466 & 0.000 & & 0.000 & 0.099 & 0.828 & 00.000 & 0.905 \\
\hline \multicolumn{9}{|l|}{ BMI } \\
\hline Correlation coefficient & $0.117^{* *}$ & $-0.141^{* *}$ & $0.931^{* *}$ & 1 & $-0.104^{* *}$ & 0.025 & $0.130 * *$ & 0.066 \\
\hline$p$-value & 0.003 & 0.000 & 0.000 & & 0.007 & 0.524 & 0.001 & 0.100 \\
\hline \multicolumn{9}{|l|}{ STA } \\
\hline Correlation coefficient & -0.035 & $0.104^{* *}$ & -0.064 & $-0.104^{* *}$ & 1 & -0.051 & 0.068 & -0.024 \\
\hline$p$-value & 0.376 & 0.008 & 0.099 & 0.007 & & 0.190 & 0.091 & 0.547 \\
\hline \multicolumn{9}{|l|}{ SKA } \\
\hline Correlation coefficient & -0.009 & $-0.087^{*}$ & -0.008 & 0.025 & -0.051 & 1 & -0.075 & 0.012 \\
\hline$p$-value & 0.818 & 0.026 & 0.828 & 0.524 & 0.190 & & 0.061 & 0.769 \\
\hline \multicolumn{9}{|l|}{$\mathrm{PMl}$} \\
\hline Correlation coefficient & -0.025 & $0.088^{*}$ & $0.164^{* *}$ & $0.130^{* *}$ & 0.068 & -0.075 & 1 & $-0.110^{* *}$ \\
\hline$p$-value & 0.536 & 0.030 & 0.000 & 0.001 & 0.091 & 0.061 & & 0.007 \\
\hline \multicolumn{9}{|l|}{ Delivery } \\
\hline Correlation coefficient & $0.487^{* *}$ & $-0.205^{* *}$ & -0.005 & 0.066 & -0.024 & 0.012 & $-0.110^{* *}$ & 1 \\
\hline$p$-value & 0.000 & 0.000 & 0.905 & 0.100 & 0.547 & 0.769 & 0.007 & \\
\hline
\end{tabular}

BMI, body mass index; STA, sacral table angle; SKA, sacral kyphosis angle; PMI, pelvic mass index.

${ }^{*}$ Correlation is significant at a $p$-value of $0.05 ;{ }^{* *}$ Correlation is significant at a $p$-value of 0.01 .

Although a relationship between LBP and IDD has been suggested [27], it is difficult to establish that pregnancy and delivery can ultimately result in IDD.

The results of the present study, similar to past research, indicated a strong correlation between IDD and age, but also between age and the number of deliveries. Therefore, we excluded the factor of age in order to assess only the relationship between the number of deliveries and IDD. We noted a significant difference in the average number of deliveries in subjects aged $<30$ years. However, a significant age difference was noted among this group, indicating that this effect may be caused by the age difference in the present population. However, in other groups without significant differences in age, we did not observe significant difference in the number of deliveries. There- fore, pregnancy is not believed to be a risk factor for IDD.

During pregnancy, an increase in the uterus size is accompanied by increased mobility of the pelvic joint, which is considered to be a factor in pelvic pain [28]. Moreover, stretching of the abdominal wall and changes in posture are believed to cause LBP [29]. In pregnant women, if the uterus can apply a mechanical stress on the pelvis, it appears reasonable that a similar amount of stress could be exerted by a uterine leiomyoma, which is a representative intrapelvic space-occupying lesion. However, the current results did not show any significant differences between subjects with IDD and those without IDD in terms of the size of intrapelvic space-occupying lesions or the presence of uterine leiomyoma, indicating that these factors did not influence IDD. Although uter- 
Table 3. Comparison of the disc degeneration-positive and -negative groups

\begin{tabular}{|c|c|c|c|}
\hline Variable & Positive ( $n=405)$ & Negative $(n=255)$ & $p$-value \\
\hline \multicolumn{4}{|l|}{ All cases } \\
\hline Age (yr) & $54.21 \pm 14.66$ & $38.73 \pm 12.08$ & $<0.001^{b)}$ \\
\hline Height (cm) & $156.6 \pm 6.5$ & $158.3 \pm 5.5$ & $<0.001^{a)}$ \\
\hline Weight (kg) & $55.8 \pm 12.2$ & $53.7 \pm 9.5$ & $<0.001^{\mathrm{a})}$ \\
\hline $\mathrm{BMI}\left(\mathrm{kg} / \mathrm{m}^{2}\right)$ & $22.8 \pm 5.3$ & $21.5 \pm 3.9$ & $<0.001^{\text {a) }}$ \\
\hline $\operatorname{STA}\left({ }^{\circ}\right)$ & $101.1 \pm 6.4$ & $100.5 \pm 5.4$ & $0.211^{b)}$ \\
\hline $\operatorname{SKA}\left({ }^{\circ}\right)$ & $163.0 \pm 11.2$ & $163.3 \pm 15.0$ & $0.721^{\mathrm{a})}$ \\
\hline UL & & & $0.203^{\mathrm{cl}}$ \\
\hline Present (\%) & $184(27.9)$ & $103(15.6)$ & \\
\hline Absent (\%) & $221(33.5)$ & $152(23.0)$ & \\
\hline PMI $\left(\mathrm{mm}^{2}\right)$ & $6482.9 \pm 5543.6$ & $5960.5 \pm 4871.5$ & $0.235^{\mathrm{a})}$ \\
\hline Delivery (range) & $1.27(0-6)$ & $0.68(0-4)$ & $<0.001^{d)}$ \\
\hline \multicolumn{4}{|l|}{ Age $\leq 30$ group (yr) } \\
\hline Number & 14 & 63 & - \\
\hline Age (yr) & $25.86 \pm 3.33$ & $22.84 \pm 4.81$ & $0.029^{\mathrm{a})}$ \\
\hline Height (cm) & $159.1 \pm 4.6$ & $159.0 \pm 5.7$ & $0.915^{\mathrm{a})}$ \\
\hline Weight (kg) & $54.1 \pm 7.0$ & $52.0 \pm 9.4$ & $0.43^{\mathrm{a})}$ \\
\hline $\mathrm{BMI}\left(\mathrm{kg} / \mathrm{m}^{2}\right)$ & $21.4 \pm 2.9$ & $20.6 \pm 3.7$ & $0.434^{\mathrm{al}}$ \\
\hline $\operatorname{STA}\left({ }^{\circ}\right)$ & $102.6 \pm 9.1$ & $100.7 \pm 5.5$ & $0.475^{b)}$ \\
\hline SKA $\left({ }^{\circ}\right)$ & $159.3 \pm 10.7$ & $165.2 \pm 10.7$ & $0.067^{\mathrm{a})}$ \\
\hline UL & & & $0.597^{c)}$ \\
\hline Present (\%) & $2(2.6)$ & $6(7.8)$ & \\
\hline Absent (\%) & 12 (15.6) & $57(74.0)$ & \\
\hline $\mathrm{PMI}\left(\mathrm{mm}^{2}\right)$ & $6489.1 \pm 6557.4$ & $3860.8 \pm 3101.0$ & $0.221^{\mathrm{bl}}$ \\
\hline Delivery (range) & $0.46(0-2)$ & $0.05(0-1)$ & $0.003^{\mathrm{d})}$ \\
\hline \multicolumn{4}{|c|}{ Age 30-39 group (yr) } \\
\hline Number & 43 & 61 & - \\
\hline Age (y) & $36.14 \pm 2.68$ & $35.23 \pm 2.91$ & $0.107^{\mathrm{a})}$ \\
\hline Height (cm) & $161.3 \pm 5.4$ & $158.7 \pm 5.4$ & $0.018^{\mathrm{a})}$ \\
\hline Weight (kg) & $56.8 \pm 8.4$ & $53.3 \pm 7.7$ & $0.029^{\mathrm{a})}$ \\
\hline $\mathrm{BMI}\left(\mathrm{kg} / \mathrm{m}^{2}\right)$ & $21.9 \pm 3.1$ & $21.2 \pm 3.0$ & $0.261^{\mathrm{a})}$ \\
\hline $\operatorname{STA}\left({ }^{\circ}\right)$ & $101.3 \pm 8.6$ & $101.5 \pm 6.7$ & $0.929^{a)}$ \\
\hline $\operatorname{SKA}\left({ }^{\circ}\right)$ & $163.5 \pm 11.6$ & $162.8 \pm 10.4$ & $0.741^{\mathrm{a})}$ \\
\hline UL & & & $0.863^{c)}$ \\
\hline Present (\%) & 19 (18.3) & 28 (26.9) & \\
\hline Absent (\%) & $24(23.1)$ & 33 (31.7) & \\
\hline $\mathrm{PMI}\left(\mathrm{mm}^{2}\right)$ & $6722.0 \pm 4620.3$ & $5813.9 \pm 3679.6$ & $0.277^{\mathrm{a})}$ \\
\hline Delivery (range) & $0.54(0-2)$ & $0.52(0-4)$ & $0.370^{d / d}$ \\
\hline
\end{tabular}


Table 3. Continued

\begin{tabular}{|c|c|c|c|}
\hline Variable & Positive (n=405) & Negative ( $n=255)$ & $p$-value \\
\hline \multicolumn{4}{|l|}{ Age 40-49 group (yr) } \\
\hline Number & 120 & 92 & - \\
\hline Age (yr) & $44.70 \pm 2.99$ & $44.05 \pm 2.74$ & $0.108^{\mathrm{a})}$ \\
\hline Height (cm) & $158.5 \pm 5.7$ & $158.33 \pm 5.8$ & $0.795^{\mathrm{a})}$ \\
\hline Weight (kg) & $59.4 \pm 13.9$ & $54.1 \pm 9.3$ & $0.001^{b)}$ \\
\hline $\mathrm{BMI}\left(\mathrm{kg} / \mathrm{m}^{2}\right)$ & $23.7 \pm 5.9$ & $21.6 \pm 4.2$ & $0.005^{b)}$ \\
\hline STA $\left(^{\circ}\right)$ & $101.2 \pm 6.1$ & $99.9 \pm 4.6$ & $0.079^{b)}$ \\
\hline SKA $\left(^{\circ}\right)$ & $163.5 \pm 10.7$ & $164.0 \pm 20.2$ & $0.822^{a)}$ \\
\hline $\mathrm{UL}$ & & & $0.176^{c)}$ \\
\hline Present (\%) & $80(37.7)$ & $53(25.0)$ & \\
\hline Absent (\%) & 40 (18.9) & $39(18.4)$ & \\
\hline PMI $\left(\mathrm{mm}^{2}\right)$ & $8123.4 \pm 55131.7$ & $6954.4 \pm 4369.6$ & $0.087^{a)}$ \\
\hline Delivery (range) & $0.90(0-4)$ & $0.88(0-3)$ & $0.910^{\mathrm{d})}$ \\
\hline \multicolumn{4}{|l|}{ Age 50-59 group (yr) } \\
\hline Number & 87 & 27 & - \\
\hline Age (yr) & $53.59 \pm 3.01$ & $53.81 \pm 2.76$ & $0.726^{a)}$ \\
\hline Height (cm) & $157.3 \pm 5.7$ & $157.2 \pm 4.2$ & $0.916^{a)}$ \\
\hline Weight (kg) & $55.7 \pm 14.7$ & $54.7 \pm 11.4$ & $0.749^{a)}$ \\
\hline $\mathrm{BMI}\left(\mathrm{kg} / \mathrm{m}^{2}\right)$ & $22.4 \pm 5.4$ & $22.1 \pm 4.0$ & $0.734^{a)}$ \\
\hline STA $\left(^{\circ}\right)$ & $101.6 \pm 6.2$ & $100.2 \pm 5.3$ & $0.285^{\text {a) }}$ \\
\hline $\operatorname{SKA}\left({ }^{\circ}\right)$ & $161.3 \pm 11.6$ & $160.1 \pm 13.5$ & $0.649^{\mathrm{a})}$ \\
\hline UL & & & $0.908^{\mathrm{cl}}$ \\
\hline Present (\%) & $43(37.7)$ & $13(11.4)$ & \\
\hline Absent (\%) & 44 (38.6) & 14 (12.3) & \\
\hline PMI $\left(\mathrm{mm}^{2}\right)$ & $6318.9 \pm 4718.7$ & $6098.7 \pm 4797.4$ & $0.838^{\text {a) }}$ \\
\hline Delivery (range) & $1.36(0-4)$ & $1.36(0-4)$ & $0.997^{d)}$ \\
\hline \multicolumn{4}{|l|}{ Age $\geq 60$ group (yr) } \\
\hline Number & 141 & 12 & - \\
\hline Age (yr) & $71.01 \pm 7.80$ & $65.25 \pm 5.93$ & $0.014^{a)}$ \\
\hline Height (cm) & $152.6 \pm 5.9$ & $153.9 \pm 3.0$ & $0.428^{b)}$ \\
\hline Weight (kg) & $52.8 \pm 12.6$ & $58.4 \pm 13.3$ & $0.140^{\mathrm{a})}$ \\
\hline $\mathrm{BMI}\left(\mathrm{kg} / \mathrm{m}^{2}\right)$ & $22.7 \pm 5.4$ & $24.6 \pm 5.1$ & $0.241^{\text {a) }}$ \\
\hline STA $\left(^{\circ}\right)$ & $100.4 \pm 5.6$ & $100.1 \pm 4.2$ & $0.832^{\text {a) }}$ \\
\hline SKA $\left(^{\circ}\right)$ & $163.7 \pm 11.3$ & $158.6 \pm 8.5$ & $0.128^{a)}$ \\
\hline \multicolumn{4}{|l|}{ UL } \\
\hline Present (\%) & $40(26.1)$ & $3(2.0)$ & $0.803^{c)}$ \\
\hline Absent (\%) & $101(66.0)$ & $9(5.9)$ & \\
\hline $\mathrm{PMI}\left(\mathrm{mm}^{2}\right)$ & $4918.3 \pm 6238.1$ & $8738.5 \pm 13508.0$ & $0.099^{b)}$ \\
\hline Delivery (range) & $1.85(0-6)$ & $1.64(0-3)$ & $0.563^{d)}$ \\
\hline
\end{tabular}

BMI, body mass index; STA, sacral table angle; SKA, sacral kyphosis angle; UL, uterine leiomyoma; PMI, pelvic mass index.

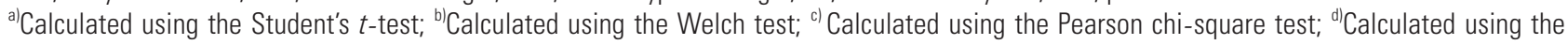
Mann-Whitney test. 
Table 4. Results of logistic regression analysis of the risk factors for IDD (all included cases)

\begin{tabular}{lcc} 
Variable & Odds ratio $(95 \% \mathrm{CI})$ & $p$-value \\
\hline Age & $1.095(1.076-1.114)$ & $<0.001$ \\
BMI & $1.056(1.007-1.106)$ & 0.023 \\
STA & $1.034(1.003-1.067)$ & 0.034 \\
UL & $1.034(0.708-1.573)$ & 0.793 \\
PMI & $1.000(1.000-1.000)$ & 0.592 \\
Constant & -8.371 & $<0.001$ \\
\hline
\end{tabular}

IDD, intervertebral disc degeneration; Cl, confidence interval; BMI, body mass index; STA, sacral table angle; UL, uterine leiomyoma; PMI, pelvic mass index.

ine leiomyomas may be present for a long period or may be of considerable size, they are believed to have only minimal influence on the intervertebral discs. In women, a decrease in the estrogen levels due to aging is believed to be involved in degeneration of the musculoskeletal system, and estrogen supplementation is believed to prevent IDD [30]. The maintenance of estrogen secretion as a means to prevent IDD has been suggested based on the fact that a mass with similar size to that of a uterine leiomyoma may persist.

The present study has certain limitations. One limitation is the retrospective design, where the height and weight data obtained did not always match the timing of the imaging exam. Most of the data was acquired at the time of first consultation. However, the effect of weight and height to IDD is a long-term one, and therefore the time-lag between the data acquisition and MRI exam may not influence the results. Current study lacked information on the symptoms related to LBP, which would have facilitated the analysis of the relationship between IDD and these symptoms. It should also be mentioned that the evaluated MRI images included only T2-weighted sagittal images, which limited the discs available for evaluation to the L5-S1 portion. Examination of other discs and measurement of spinopelvic sagittal parameters including sacral slope and pelvic tilt on lateral standing X-ray could have produced additional findings.

\section{Conclusions}

As noted in prior studies, the current findings indicate that aging is the primary cause of IDD in Japanese wom- en. We also noted that BMI is involved in the development of IDD. With regard to the sacral structural indices, no effect of SKA was noted, and the influence of STA was found to be minimal. The present study is the first to indicate that the gynecological background, in terms of the number of deliveries, size of intrapelvic lesions, and presence of uterine leiomyoma, does not influence the occurrence of IDD.

\section{Conflict of Interest}

No potential conflict of interest relevant to this article was reported.

\section{Acknowledgments}

We thank Kae Okumura and Kazumi Kawamura for their support with clinical data acquisition.

\section{References}

1. Cheung KM, Karppinen J, Chan D, et al. Prevalence and pattern of lumbar magnetic resonance imaging changes in a population study of one thousand fortythree individuals. Spine (Phila Pa 1976) 2009;34:93440.

2. Jensen MC, Brant-Zawadzki MN, Obuchowski N, Modic MT, Malkasian D, Ross JS. Magnetic resonance imaging of the lumbar spine in people without back pain. N Engl J Med 1994;331:69-73.

3. Powell MC, Wilson M, Szypryt P, Symonds EM, Worthington BS. Prevalence of lumbar disc degeneration observed by magnetic resonance in symptomless women. Lancet 1986;2:1366-7.

4. Nachemson A, Lewin T, Maroudas A, Freeman MA. In vitro diffusion of dye through the end-plates and the annulus fibrosus of human lumbar inter-vertebral discs. Acta Orthop Scand 1970;41:589-607.

5. Holm S, Nachemson A. Variations in the nutrition of the canine intervertebral disc induced by motion. Spine (Phila Pa 1976) 1983;8:866-74.

6. Oda H, Matsuzaki H, Tokuhashi Y, Wakabayashi K, Uematsu Y, Iwahashi M. Degeneration of intervertebral discs due to smoking: experimental assessment in a rat-smoking model. J Orthop Sci 2004;9:135-41.

7. Takatalo J, Karppinen J, Taimela S, et al. Body mass index is associated with lumbar disc degeneration in 
young Finnish males: subsample of Northern Finland birth cohort study 1986. BMC Musculoskelet Disord 2013;14:87.

8. Weiler C, Lopez-Ramos M, Mayer HM, et al. Histological analysis of surgical lumbar intervertebral disc tissue provides evidence for an association between disc degeneration and increased body mass index. BMC Res Notes 2011;4:497.

9. McCarthy SM, Filly RA, Stark DD, et al. Obstetrical magnetic resonance imaging: fetal anatomy. Radiology 1985;154:427-32.

10. Ergun T, Lakadamyali H, Sahin MS. The relation between sagittal morphology of the lumbosacral spine and the degree of lumbar intervertebral disc degeneration. Acta Orthop Traumatol Turc 2010;44:293-9.

11. Kanat A, Yazar U, Kazdal H, Sonmez OF. Introducing a new risk factor for lumbar disc herniation in females: vertical angle of the sacral curvature. J Korean Neurosurg Soc 2012;52:447-51.

12. Pfirrmann CW, Metzdorf A, Zanetti M, Hodler J, Boos N. Magnetic resonance classification of lumbar intervertebral disc degeneration. Spine (Phila Pa 1976) 2001;26:1873-8.

13. Takatalo J, Karppinen J, Niinimaki J, et al. Prevalence of degenerative imaging findings in lumbar magnetic resonance imaging among young adults. Spine (Phila Pa 1976) 2009;34:1716-21.

14. Takatalo J, Karppinen J, Taimela S, et al. Association of abdominal obesity with lumbar disc degeneration-a magnetic resonance imaging study. PLoS One 2013;8:e56244.

15. Osterman K, Osterman H. Experimental lumbar spondylolisthesis in growing rabbits. Clin Orthop Relat Res 1996;(332):274-80.

16. Battie MC, Videman T. Lumbar disc degeneration: epidemiology and genetics. J Bone Joint Surg Am 2006;88 Suppl 2:3-9.

17. Videman T, Battie MC, Parent E, Gibbons LE, Vainio P, Kaprio J. Progression and determinants of quantitative magnetic resonance imaging measures of lumbar disc degeneration: a five-year follow-up of adult male monozygotic twins. Spine (Phila Pa 1976) 2008;33:1484-90.

18. Williams FM, Popham M, Sambrook PN, Jones AF, Spector TD, MacGregor AJ. Progression of lumbar disc degeneration over a decade: a heritability study. Ann Rheum Dis 2011;70:1203-7.
19. Hassett G, Hart DJ, Manek NJ, Doyle DV, Spector TD. Risk factors for progression of lumbar spine disc degeneration: the Chingford Study. Arthritis Rheum 2003;48:3112-7.

20. Hangai M, Kaneoka K, Kuno S, et al. Factors associated with lumbar intervertebral disc degeneration in the elderly. Spine J 2008;8:732-40.

21. Liuke M, Solovieva S, Lamminen A, et al. Disc degeneration of the lumbar spine in relation to overweight. Int J Obes (Lond) 2005;29:903-8.

22. Bastiaanssen JM, de Bie RA, Bastiaenen CH, Essed GG, van den Brandt PA. A historical perspective on pregnancy-related low back and/or pelvic girdle pain. Eur J Obstet Gynecol Reprod Biol 2005;120:3-14.

23. Kovacs FM, Garcia E, Royuela A, Gonzalez L, Abraira V; Spanish Back Pain Research Network. Prevalence and factors associated with low back pain and pelvic girdle pain during pregnancy: a multicenter study conducted in the Spanish National Health Service. Spine (Phila Pa 1976) 2012;37:1516-33.

24. Mogren IM, Pohjanen AI. Low back pain and pelvic pain during pregnancy: prevalence and risk factors. Spine (Phila Pa 1976) 2005;30:983-91.

25. Gruber HE, Buchanan L, Ingram JA, Zinchenko N, Norton HJ, Hanley EN Jr. The relationship between pregnancy-associated plasma protein-A (PAPP-A) and human intervertebral disc degeneration. Histol Histopathol 2010;25:1431-6.

26. Svensson HO, Andersson GB, Hagstad A, Jansson PO. The relationship of low-back pain to pregnancy and gynecologic factors. Spine (Phila Pa 1976) 1990;15:371-5

27. Livshits G, Popham M, Malkin I, et al. Lumbar disc degeneration and genetic factors are the main risk factors for low back pain in women: the UK Twin Spine Study. Ann Rheum Dis 2011;70:1740-5.

28. Mens JM, Pool-Goudzwaard A, Stam HJ. Mobility of the pelvic joints in pregnancy-related lumbopelvic pain: a systematic review. Obstet Gynecol Surv 2009;64:200-8.

29. Dumas GA, Reid JG, Wolfe LA, Griffin MP, McGrath MJ. Exercise, posture, and back pain during pregnancy. Clin Biomech (Bristol, Avon) 1995;10:98-103.

30. Calleja-Agius J, Muscat-Baron Y, Brincat MP. Estrogens and the intervertebral disc. Menopause Int 2009;15:127-30. 